\title{
'Kanoo', a Traditional Urban Neighborhood in Manama City: An Approach to Promote Urban Regeneration and Enhance Livability
}

\author{
Fatima Shubbar ${ }^{1}$, Dr. Raffaello Furlan ${ }^{2 *}$
}

${ }^{1}$ Architect, B.Sc. Arch - University of Bahrain (Kingdom of Bahrain) Master in Urban Planning and Design (MUPD) Candidate, College of Engineering, Department of Architecture and Urban Planning, Qatar University

${ }^{2}$ Architect, PhD - Griffith University (Australia), BArch, MArch - IUAV (Italy) Assistant Professor, College of Engineering, Department of Architecture and Urban Planning, Qatar University

DOI: $10.36348 /$ SJCE.2019.v03i05.003

| Received: 09.09.2019 | Accepted: 17.09.2019| Published: 29.09.2019

*Corresponding author: Raffaello Furlan

\section{Abstract}

Cities all over the world are currently facing many challenges and obstacles related to economy, society, and environment. These were the results of rapid economic developments, urban and population growth, and the accompanying increased needs and changing lifestyles. Several decades ago, Manama, the capital of the Kingdom of Bahrain, experienced significant changes in its urban form due to economic, cultural, and environmental factors. These changes appeared specifically after the discovery of oil in 1932, and the transformation of the economy from fishing and pearl trading to one based on oil. Currently, the Kingdom of Bahrain is investing in its capacity and solutions to these challenges, including creating major attractive developments to meet human needs and nourish the economy. Traditional urban neighborhoods across Bahrain, such as Kanoo, a traditional neighborhood located in Old Manama, were severely affected by modern developments. This research study investigates the urban design study of the Kanoo neighborhood, its features, the urban and historical significance in Manama and its surroundings. The study further investigates the role of rehabilitation projects in regenerating the old core of Manama, while rebuilding the vanishing identity of the city. The findings highlight the critical factors effecting the Kanoo neighborhood and contribute to develop strategies for a sustainable urban regeneration approach, enabling to protect the urban fabric of the neighborhood and its remaining historical areas, to revive the old city and preserve the neighborhood's identity.

Keywords: Urban Neighborhood, Sustainable Urban Regeneration, Built Heritage, Old Manama, Kanoo.

Copyright @ 2019: This is an open-access article distributed under the terms of the Creative Commons Attribution license which permits unrestricted use, distribution, and reproduction in any medium for non-commercial use (NonCommercial, or CC-BY-NC) provided the original author and source are credited.

\section{INTRODUCTION}

Scholars argue that there are several challenges facing cities and affecting the process of urbanization, urban growth and socio-spatial dynamics in urban settlements. These challenges could be related to the economy such as resource scarcity and unemployment, and/or to the environment such as pollution and global warming, or to crime and poverty. These factors contribute to significantly reshape towns and cities in the GCC [1-5].

Since the beginning of the twentieth century, cities worldwide have experienced massive urban growth. In the Gulf region specifically, cities have witnessed rapid increases in population and urbanization due to the exploitation of oil resources in the late 1930s. The discovery of oil has transformed the cities' economy from primitive to oil dependent. As a result, cities' needs have changed, requiring more urban developments and causing major transformation in the urban fabric. Citizens have abandoned their old traditional neighborhoods, to move into new modern settlements, and look for job opportunities. Consequently, these old neighborhoods have experienced severe damage and deterioration from abandonment and neglect [6-10].

'Kanoo' is an old neighborhood located in Manama city, the capital of the Kingdom of Bahrain. It is one of these abandoned neighborhoods mainly because of the immigration of Bahraini families to modern new towns that meet their needs, and the invasion of labors into the abandoned properties. As a result, the urban heritage which is the core of the city that reflects its history and identity has been neglected.

For the past 10 years, urban regeneration projects have been established in Manama city by the Bahrain Authority for Culture and Antiquities and by some private owners. Such projects included the Old 
Manama Souq and Manama Post Office Museum. These projects were created mainly to preserve the historical structures along with the identity associated with them. Although these urban regeneration projects have conserved some of the old houses and structures, they lack comprehensiveness and are not correlated or connected to the surroundings [11].

The aim of this research study is to investigate the factors affecting the Kanoo neighborhood and develop a strategy to revitalize the area. The methodology implemented in this research study was both qualitative and quantitative, along with a review of literature and case-study analysis, followed by comprehensive analysis of the Kanoo neighborhood through pictures and maps. These methods served as a background for developing strategies for a comprehensive sustainable urban regeneration approach.

\section{LITERATURE REVIEW}

The Kingdom of Bahrain is a small country that is strategically located in the Arabian Gulf with an area of about 700 square kilometres. It is an archipelago consisting of 36 islands surrounding a main island (Figure 1). Manama is the capital city, and it developed adjacent to the north coast of the main island, and overlooking the Gulf. Simultaneously, another city grew along with Manama. Muharraq is on an island adjacent to Manama, and connected to it by three bridges. Manama and Muharraq were assumed to be evolving concurrently and were therefore considered as twin cities [12-15].

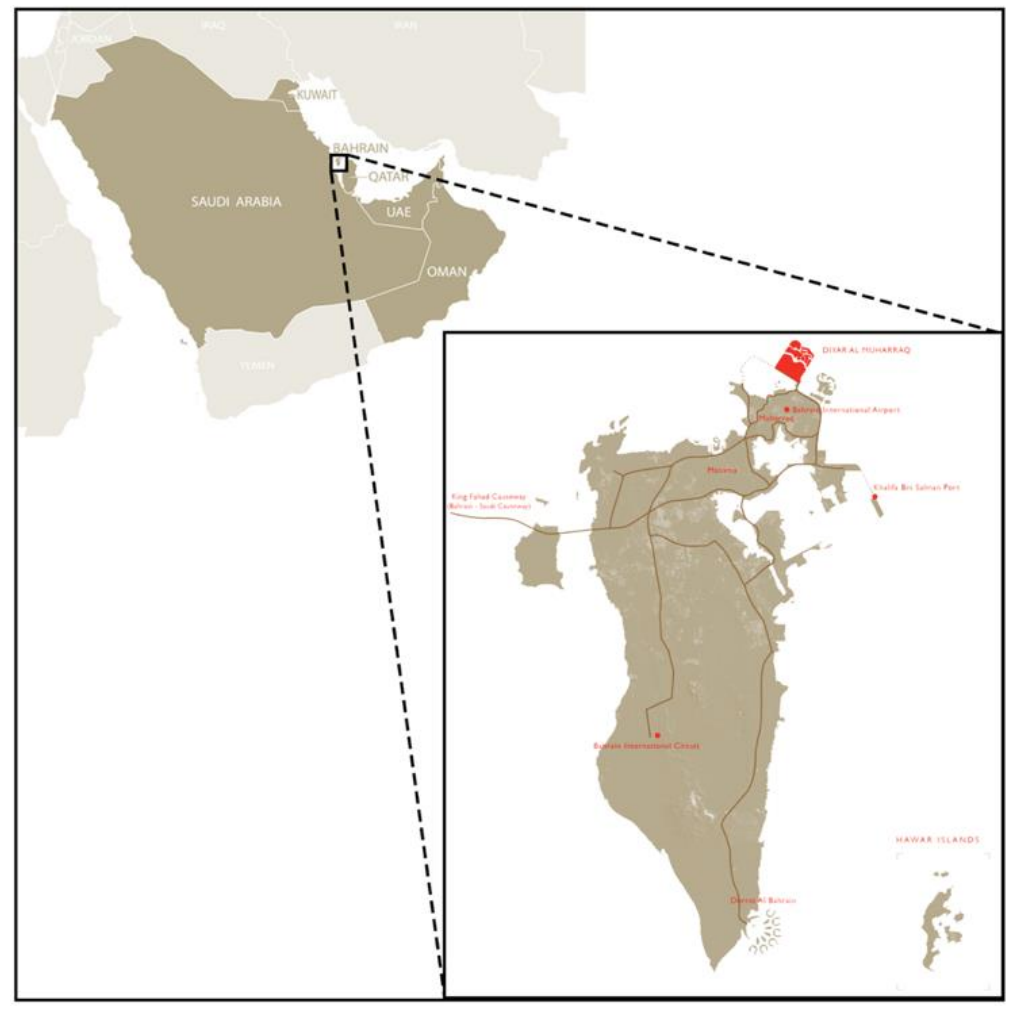

Fig-1: Map of Bahrain. Source: Authors.

Before the discovery of oil in Bahrain in 1932, the economy in Bahrain was mainly dependent on its location next to the sea and the fertility of the land, which enabled the agriculture, fishing, pearling, and shipbuilding industries to flourish. Later, the country's main income was through oil and natural gas industry[13]. The usage of these natural resources had many side effects in addition to the advantages. Many issues related to the environment, economy, and society occurred. Many industries depending on the oil industry have evolved, replacing the early economic elements which have gradually dissolved. Simultaneously, the urban morphology was affected; many modern buildings appeared along with a series of mega-projects and skyscrapers.

These have all affected the urban fabric of old Bahrain, specifically the traditional neighborhoods in Manama and Muharraq. Automobiles invaded the alleys which were specific to pedestrian movement and were not designed to accommodate cars. The encroachment of cars parked on the pathways due to lack of parking lots created overcrowding. The society became dependent on the traveling by car instead of walking and using public transportation [16, 14]. 
Because of the growing population and urbanization, as well as new institutions and companies developing in other cities, new housing units were given to citizens in new modern towns to reduce crowd by relocating people away from Manama (Table 1). Thus, nuclear families were created which affected the extended family ties. In addition, many social problems were created.

Table-1: The trend of urbanization (1941 - 1971). Source: Al-Nabi [12]

\begin{tabular}{|c|c|c|c|c|c|c|c|c|c|c|}
\hline \multirow[t]{2}{*}{ Towns } & \multicolumn{2}{|c|}{1941} & \multicolumn{2}{|c|}{1950} & \multicolumn{2}{|c|}{1959} & \multicolumn{2}{|c|}{1965} & \multicolumn{2}{|c|}{1971} \\
\hline & Рор,\% & total & Рop,\% & total & Рop,\% & total & Рop,\% & total & Рop,\% & f total \\
\hline Manama & 27835 & 30.9 & 39648 & 36.15 & 61726 & 43.12 & 79098 & 43.41 & 88785 & 41.00 \\
\hline Muharraq & 21439 & 23.8 & 25577 & 23.32 & 32302 & 22.56 & 41143 & 22.58 & 37732 & 17.44 \\
\hline Hidd & - & - & - & - & 4440 & 3.10 & 5230 & 2.87 & 5269 & 2.43 \\
\hline RiffA & - & - & - & - & 6623 & 4.62 & 9403 & 5.16 & 10731 & 4.90 \\
\hline Awali & 1532 & 1. 70 & 3846 & 3.50 & 3123 & 2.18 & 2097 & 1.15 & 984 & 0.45 \\
\hline Jidhafs & - & - & - & - & 5591 & 3.90 & 7941 & 4.35 & 11152 & 5.15 \\
\hline Isa Town & - & - & - & - & - & - & - & - & 7501 & 3.46 \\
\hline $\begin{array}{l}\text { Rural \& Other } \\
\text { areas }\end{array}$ & 39164 & 43.5 & 40579 & 37.00 & 29330 & 20.49 & 37291 & 20.46 & 54149 & 25.00 \\
\hline Total & 89970 & 99.90 & 109650 & 99.97 & 143135 & 99.97 & 182203 & 99.98 & 216303 & 99.83 \\
\hline
\end{tabular}

As a result, the old traditional neighborhoods were gradually abandoned by Bahraini citizens, giving laborers the chance to find accommodations in these old settlements and encouraging the creation of slums. Moreover, the neighborhoods were extensively used in a bad way and neglected by locals, which was a major cause of their deterioration and therefore, a lack of urban Bahraini identity [11, 17].

Within Bahrain National Vision 2030, efforts were made to ensure sustainability of the development process with regard to its environmental, economic, and social aspects. Through this national vision, the government of Bahrain seeks to ensure the long-term well-being and prosperity of all Bahrainis. It is therefore committed to the process of strategic planning to determine and understand the opportunities and limitations confronting the country so that it can create policies and identify actionable initiatives to contribute to the recognition of these strategic priorities. Institutions, agencies, and commissions were involved in the development process to achieve sustainability in various dimensions [18].
The objectives of this strategy comes in line with Bahrain National Vision 2030, and are as follows: provide a safe and satisfying environment; attain sustainable quality growth; provide adequate infrastructure; enhance the performance and efficiency of the government; provide appropriate, accessible social services; and ensure sustainable development of strategic resources [18].

Bahrain National Plan 2030 addresses issues such as natural resources, inadequate housing, lack of zoning, weak transport infrastructure, insufficient public open space and the need for improved education and comprehensive employment. The ten key strategies of Bahrain National Strategic Planning Principles are as follows: to create a single framework schema; to achieve a specialized economy in the local and global markets; to save and maintain the environmental resources; to set interrelated strategies with the variety of transportation systems; to meet housing needs; to identify the public waterfront; to protect Bahrain's cultural and archeological heritage; to meet the future requirements of the military sector; increasing the vegetation in the kingdom, and promoting a sustainable future (Figure 2) [14]. 


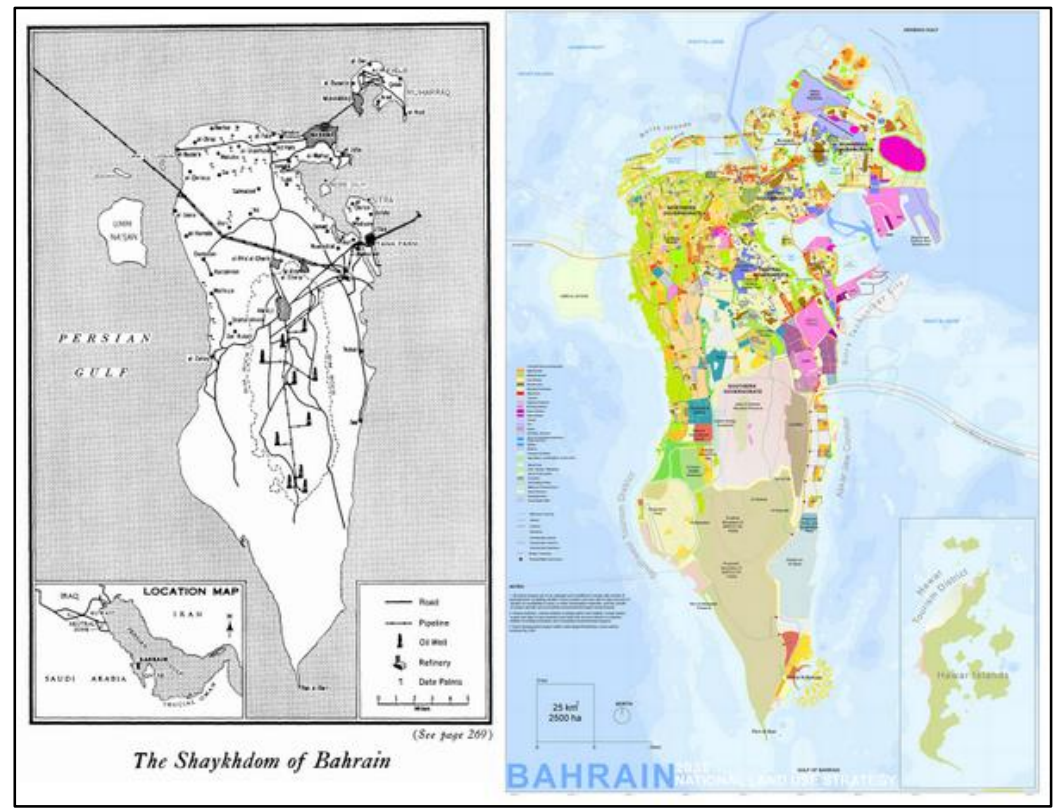

Fig-2: Bahrain's map in 1955 compared to its Vision 2030. Source: Twitter.com

Simultaneously, Bahrain launched The Economic Vision 2030 that aims to shape the vision of the economy with relevance to the vision of the government and society. That is to shift from an oilbased economy, to a more diversified economy, shaped by the government and achieved by the private sector. This will provide citizens with decent living standards via increasing productivity and high-income jobs within a safe living environment. The vision is established around three guiding principles: sustainability, fairness, and competitiveness[16].

In Bahrain, the physical urban environment consists of four primary elements: buildings, streets and cul-de-sacs, the Fereej (neighborhood), and the town as a whole. The neighborhood is both physical and psychological in nature. Physically it consists of buildings, streets, and urban spaces, which are shops, apartment/homes, places of work, recreation, education, and socializing. Psychologically it consists of family, friends, and associates. The psychological aspects often determine the level of well-being of the residents of the neighborhood. The activities that take place along the buildings' edge and within the street help determine the quality of the character and social network. These qualities are often the determining factor in the acceptance of the fereej by residents as a nice place to live, and by businesses as a possible profitable location for investment [17].

The majority of the current residents of Manama are primarily non-Bahraini. There seems to be no attachment either through family or through network of friends to this area by the non-Bahraini population. Surprisingly, there is a desire by the Bahraini who is former residents of Manama to return to their old neighborhoods. However until the negative urban environmental issues are resolved, along with the social problems associated with a high concentration of bachelor laborers, they are not prepared to return [17].

As to the physical urban environment, often no thought has been given to the design and placement of electricity sub-stations, public toilets, bus stops, and so on near important buildings and urban spaces. This leads to unsatisfactory results and hinders future improvement efforts. In addition, little thought has been given to the design of landscaping, hard paving, and street furniture near important buildings and urban spaces. This undermines the value and appearance of the buildings and urban spaces [17].

Much of the urban fabric within a neighborhood has gaps due to the collapse of older buildings caused mainly by neglect. These gaps are primarily used as uncontrolled and un-designed car parks which are visually unappealing. Where gaps in a neighborhood have been filled, these infill buildings are often of a different type and architectural style than their surroundings[17].

\section{Sustainable Urbanism}

Sustainable urbanism is branch of three movements that occurred in the late twentieth century to highlight a sustainable development. This sustainable development is an environmentally friendly movement that is not harmful, as it aims to improve the human and ecological systems on a long-term basis through the concepts of New Urbanism, Smart Growth, and Green Architecture. These movements were not comprehensive; for example, the New Urbanism movement which appeared in the beginning of the 1990s was focusing on a better-designed suburban development without incorporating green building design and landscaping. It often targeted the higherincome classes rather than creating truly urban spaces, 
and therefore cannot be considered efficient and urban. It is important to acknowledge the significance of an integrated approach to developing cities in a sustainable way [19-23].

Sustainability is more concerned with the extensive use of limited resources and efficiency in managing the ecosystem. It organizes the spatial form of towns in a way that offers options to the individual, but not at the expenses of other residents to successfully determine the outcome of their daily lives, to the extent that the layout of the town and the location of uses can exist. In this manner, 'fine grain mixed-use' in relation to the inner city is needed, as well as for the urban edge and new settlements [9, 24, 25, 26, 22].
To develop sustainable urban areas, an approach consisting of three strategies is needed. First, it is important to broaden urban regeneration of vital functions in the cities. Second, there is a need for sufficient flexibility to accommodate unexpected changes in land use. Third, urban environments should be created in way that makes them more resilient if something unexpected occurred (Figure 3). This threelayer approach leads to redefining the concept of sustainable urbanism: 'Design a sustainable urban system, which creates physical and mental space to adjust the urban form at any moment in time, anticipates uncertain, unexpected and unprecedented change, and grows stronger and becomes more resilient when uncertainty impacts on it' [23].

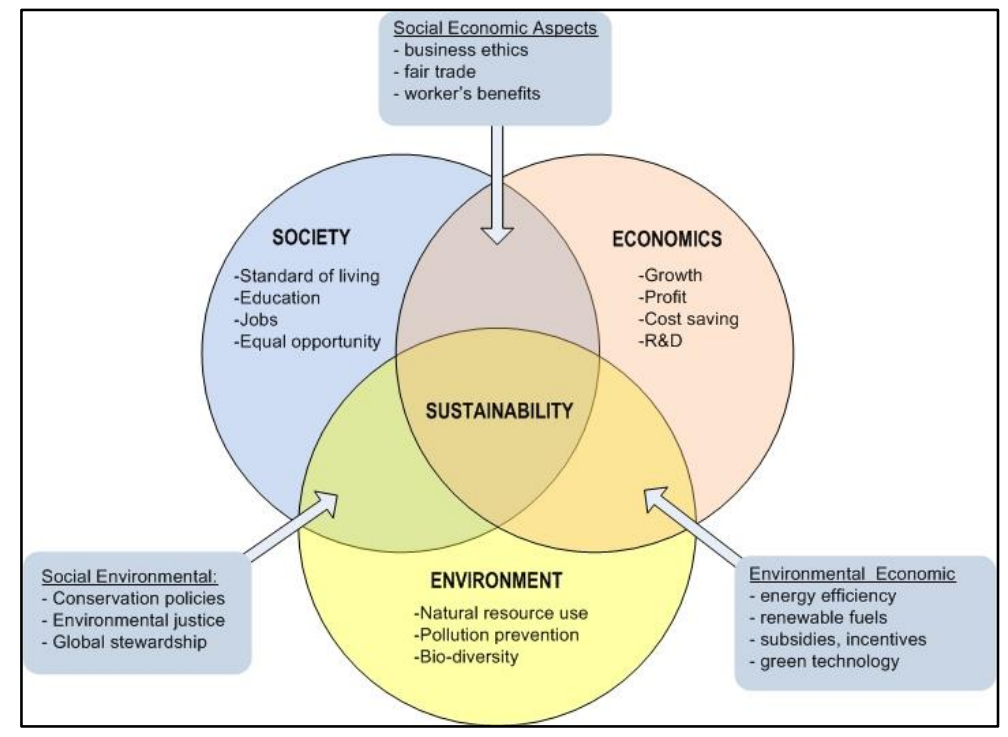

Fig-3: Pillars for achieving sustainability of cities. Source: e-education.psu.edu

This suggests the need for creating open spaces in cities that are not designed for single use. It refers to the possibility of making adjustments when needed in several periods of time, as well as the flexibility to adjust to an immediate need to change the land use. It also refers to the ability of urban areas to change function and shape, according to the growth and shrinkage of population. Good practice in urban design is to allocate at least $30 \%$ of the territory for creating adjustable spaces which are available for temporary use and flexible enough to change its use [23]. Therefore, urban design should follow these following principles:

- To regulate and allocate spaces for new, temporary or sudden use;

- To design innovative spaces that make the city stronger when facing disasters

- To create spaces that is sufficient to accommodate green and water features as well as promote regeneration for people and the ecosystem.

- To design spaces that allows the integration of human and ecological demands.

- To arrange spaces in a way that allows a closed cycle of materials, water, energy, food, and mobility [23].

\section{Urban Regeneration Based on Cultural Heritage and Local Identity}

The built environment of modern times caused all sorts of social dysfunction. During the past 50 years, most urban and suburban development has been generic, with little sense of place, history, or cultural distinctiveness [22]. Keeping urban spaces adaptable to environmental constraints and economic, social and cultural changes has been difficult, especially when meeting the social demands for upgrading social capital in a sustainable manner and for regenerating attractive urban space that is not only safe and highly efficient but also conscious of historical, cultural and local identities to guarantee a high quality of life for all [27]. The lowdensity, car-oriented, suburban-style developments were blamed for their social isolation, segregation and alienation. Therefore, cities have called for spreading the use of high-density, mixed-use planning principles which lessens the dependency on automobiles and increase social interactions [28, 9, 22].

Cultural heritage is usually referred to the selection of past elements to become sources of the present. Heritage is related to elements carrying 
meaning within them, and it is considered something precious and valuable which will be preserved and molded by contemporary concerns. Conserving this heritage also means preserving the identity of places. Currently, culture is used as a tool for regional and local development, where culture-led and culture-centered regeneration are important components in development. Cities that apply urban regeneration through the use of cultural events face the challenge of finding the right balance between social, economic, and cultural areas [29, 6, 30, 31].

Urban regeneration is tool used to improve the economic, social, physical and environmental circumstances of deprived and disadvantaged areas and households by adapting the existing built environment (Figure 4). Amongst different priorities in the context of regeneration, social regeneration means "the improved and appropriate delivery of welfare services in poor neighborhoods and the empowerment of local communities in the regeneration process" [32]. One of the major political objectives that focus on increasing the attractiveness of the regions is emphasizing the cultural dimension of cities through the concept of urban regeneration. The Culture Commission Working Paper considers cultural dimension, along with accessibility, mobility, availability of services and optimal environmental conditions as part of the competitiveness of cities by creating special urban spaces for cultural and entertainment resources, including large streams of tourists or residents [29].

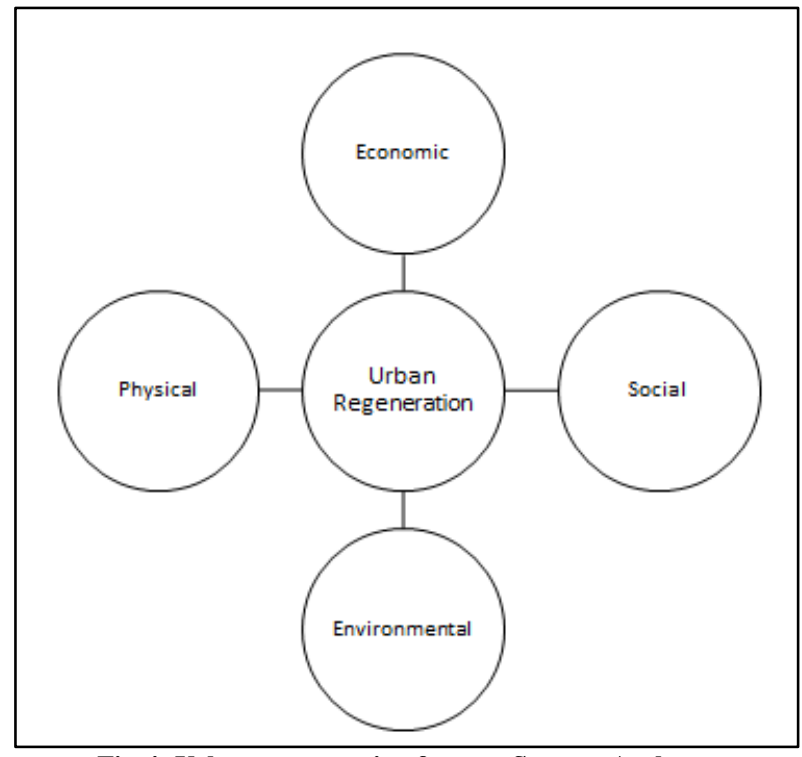

Fig-4: Urban regeneration factors. Source: Authors

Community values can be identified they along with local identity can be preserved through the conversion of buildings, which involves a complex approach to projects and intelligent interventions to the existing built environment, to preserve the history and identity of the specific urban are. The conversion appears as an approach to integrate into the social and cultural circuit, with the aim of regaining and re-using the spaces that have been abandoned and which have the potential to be transformed into centers of interest [29].

Conversion can be done on two levels: Modernization of an existing old or new structure, or functional conversion of buildings by re-dividing the interior space and remodeling the outer space.is Architectural, urban and spatial planning operations in the process of reintegration of wasted urban spaces into the modern urban fabric can be important factors contributing to the regeneration of the city. Reintegrating wasted space can also incorporate the enrichment of cultural trails, and it can include the creation of open-air museums, which are open to public access, thus they becoming genuine public spaces for art exposure [29].

Shaping attractive urban space through renevotaing existing urban space and enhancing the quality of people's life is considered as a challenge for the applying the principles of sustainable urban regeneration. In the process of urban regeneration, a plan should be created for a future vision of the urban space. The various measures must be implemented effectively and and creatively in this plan, such as, preservation and utilization of historic buildings, reconstruction and repair of old structures, creation of a safe and comfortable pedestrian and bicycle environment, development of parks and open space, creation of a beautiful landscape, an adequate number of community facilities, consideration for the environment and maintenance of safe and clean public spaces. Also, various actors, such as citizens, businesses, government departments and non-profit organizations must be engaged in the planning process of these urban spaces. Therefore, systems, procedure, and techniques, must be developed and applied to ensure collaborative and continous management of urban space by various actors[33].

\section{The Pearling Path Project in Muharraq, Bahrain}

The site consists of fifteen buildings in Muharraq, three offshore oyster beds, part of the seashore and the $\mathrm{Bu}$ Maher fort on the southern tip of Muharraq Island, where boats used to set off for the oyster beds (Figure 5). The listed buildings include residences of wealthy merchants, shops, storehouses and a mosque. They visibly indicate the major social and economic roles and institutions associated with the pearling cultural tradition and the wealth it generated at a time when the trade dominated the Gulf economy, which was from the second century to the 1930 s. Memories of that industry and its supporting social and economic structures, and the cultural identity it produced, are stimulated by these buildings. In 2012, the Pearling Path was designated by the UNESCO as a world heritage site [34]. 
The Pearling Path is a journey of 3.5 kilometres along which one can currently view 17 restored historic buildings that celebrate Muharraq's heritage. Some of the old pearling houses are still in good structural condition and can be refurbished, while others have deteriorated and needed to be removed and reconstructed. These places are the last complete examples of the cultural tradition of pearling and the wealth it generated from the second century until the early twentieth century. After UNESCO listed the Pearling Path as a world heritage site, the Bahrain Authority for Culture and Antiquities began the restoration of the entire old city of Muharraq. In addition to the Pearling Path, along with the restoration of another 600 old buildings are being restored, making the old city one of the best-preserved historic cities in the Gulf region. Both public and private sectors were involved in financing the renovations[15].

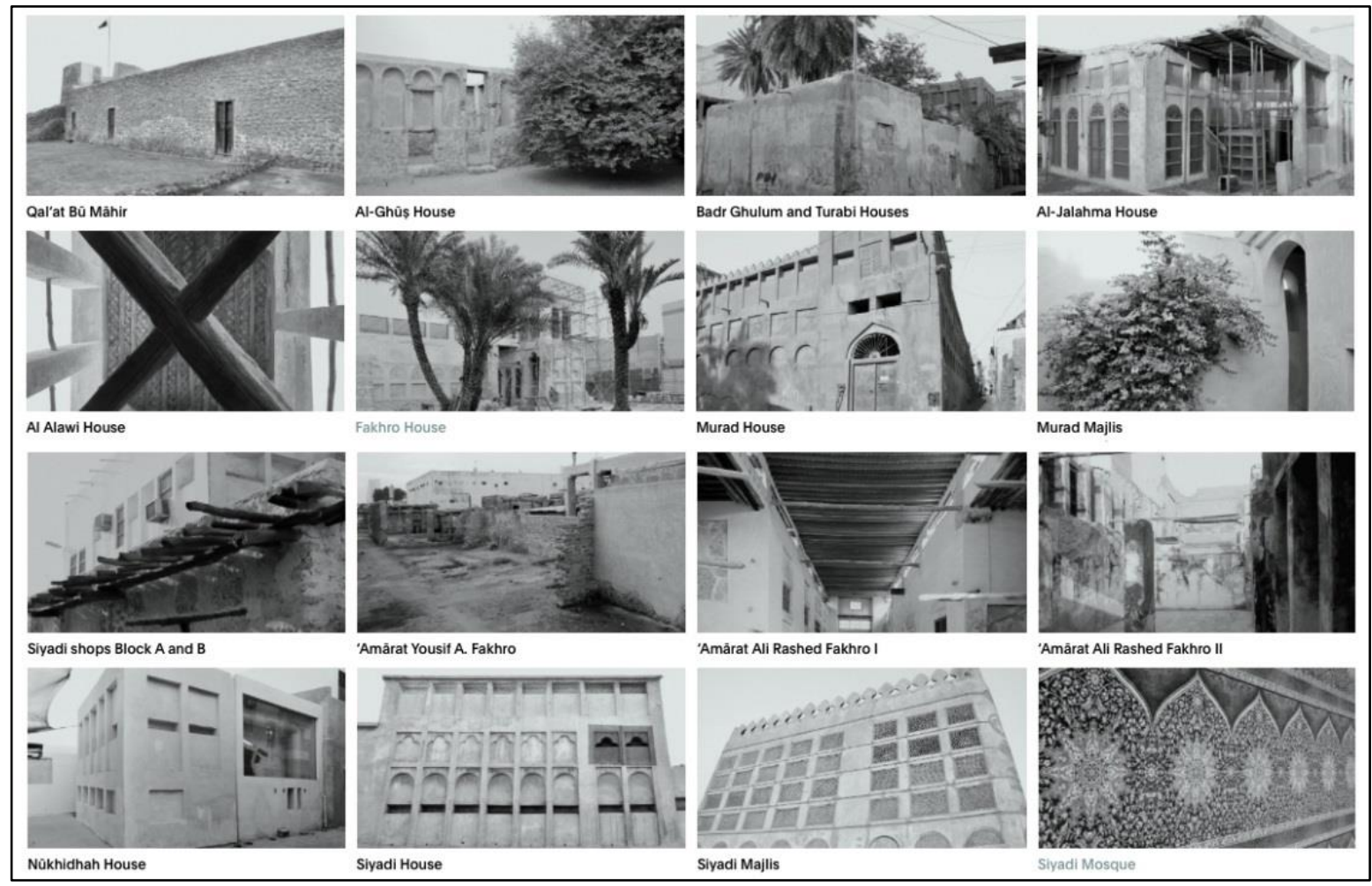

Fig-5: Pearling Pathway Sites. Source: [34]

The path officially starts from $\mathrm{Bu}$ Maher Fort, which was the historic departure point for pearl divers. The visitors are guided then from Bayt al Ghus, which was a simple pearl diver's house that has been transformed into a small museum, displaying the basic trade tools. Visitors then continue to the grand houses of the pearl merchants (Figure 6). Another destination was a coffee shop where pearl traders used to gather and play a traditional board game. Next visitors come to Mohammed bin Faris House for traditional music. The path then leads to the early twentieth century Bin Matar House, which consists of two stories and is one of the largest and most elaborate building on the trail. It reflects the importance of that family in the pearl business. The house has been fully restored and includes an art gallery for temporary exhibitions [15]. 


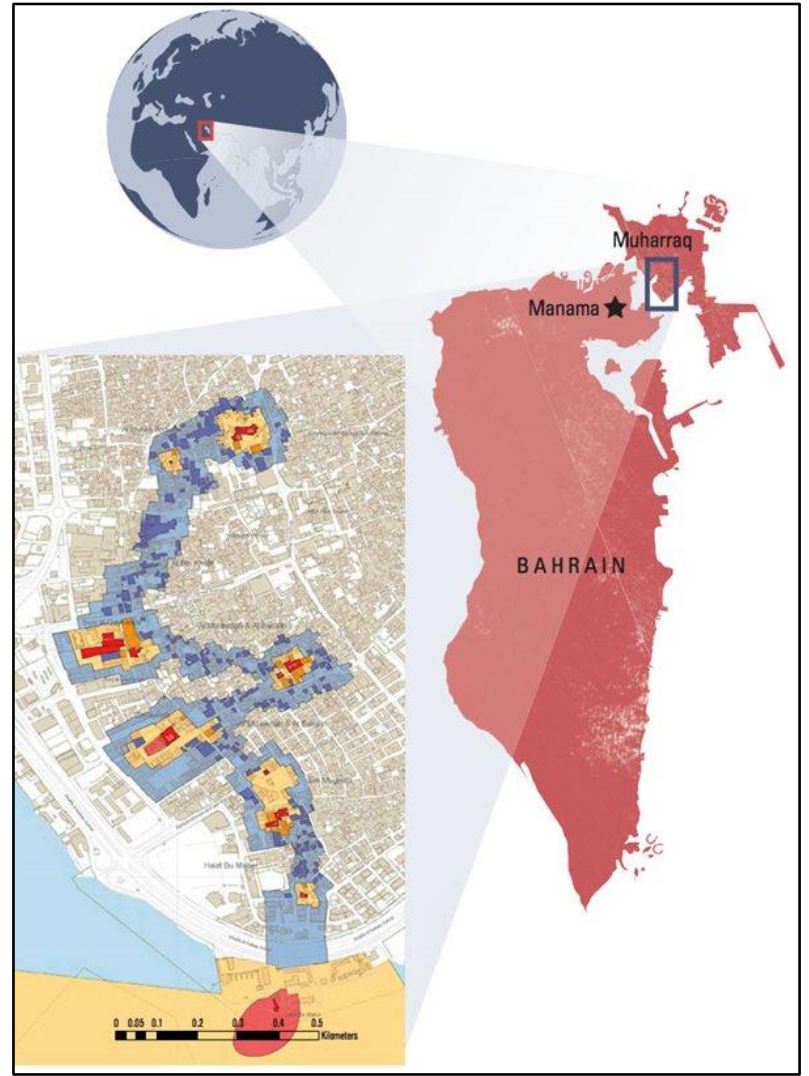

Fig-6: The Pearling Path Map. Source: [15]

These buildings are tangible manifestations of the major social and economic roles and institutions associated with the pearling society. Since the collapse of the pearl industry in the early twentieth century, most of the surviving structures have been unaltered and bear witness to distinctive building traditions characteristic of the industry. Memories of pearling industry are evoked in these buildings along with its supporting social and economic structures and cultural identity it produced. The importance of the Pearling Path goes beyond rebuilding; it a means of improving the economy by creating cultural tourism as well as making Muharraq a more pleasant place to live[34].

The urban sites chosen are still vulnerable and many buildings need extensive work before they are structurally sound. Therefore, to maintain their historic integrity, these sites needed to be stabilized and conserved with great care so that the greatest amount of original fabric is preserved by using traditional materials and processes. Then the buildings can still provide tangible links to the decades of their former glory (Figures 7 and 8). The site also relates to the wider urban context and is respected within urban Muharraq. Setting out a holistic approach for preserving the historic characters of Muharraq under two key perspectives, legal and societal. New laws were needed to be added in order to limit the increase of unplanned construction and population, prevent the deterioration of the special character of the urban fabric, and protect sites, urban settlements and antiquities [34].

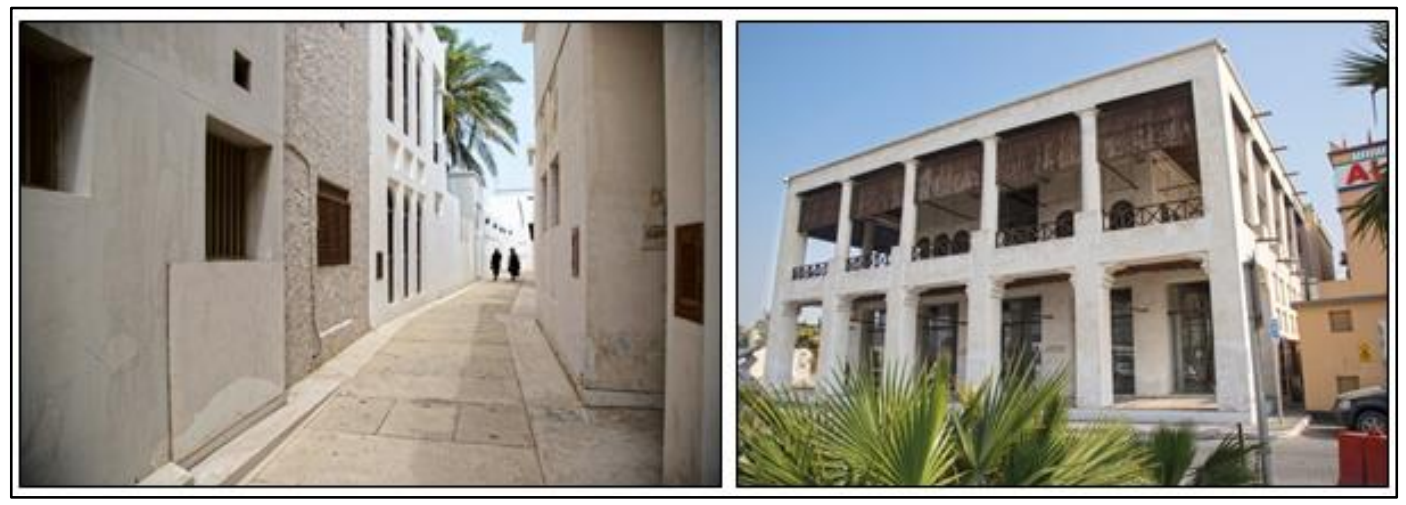

Fig-7: One of the main streets on pearling path. Source:[15] Figure 8: Bin Matar House. Source:[15]

The assessment of the site included an assessment of the significant economic, social and cultural factors, with an overall vision of activating the role of culture in social and economic development. The goals are to conserve the components of the property by using an international set of standards, to provide public access to all property components, to provide contextual knowledge about the economic, social, and cultural area, and to develop a communitybased approach in dealing with urban matters. In addition, authorities also aim preserve the shared memory of the pearling era through the documentation of its stories and fostering ongoing practices [35].
The project is progressing in different layers for each of the three main interventions in area: conservation, urban renewal, and visitor facilities. The project includes a comprehensive facade upgrade, the creation of a visitor center and an experience center for the pearling path and $\mathrm{Bu}$ Maher fort, creation of squares and public spaces, establishing the pearl museum for jewelry, setting up a service to provide boat visits to the fort and seashore, and creating culture and art festivals. Additionally, mobility and traffic arrangements of four multistory car parks were included within the scope of project. Figure 9 shows a summary of The Pearling Path case study analysis [35]. 


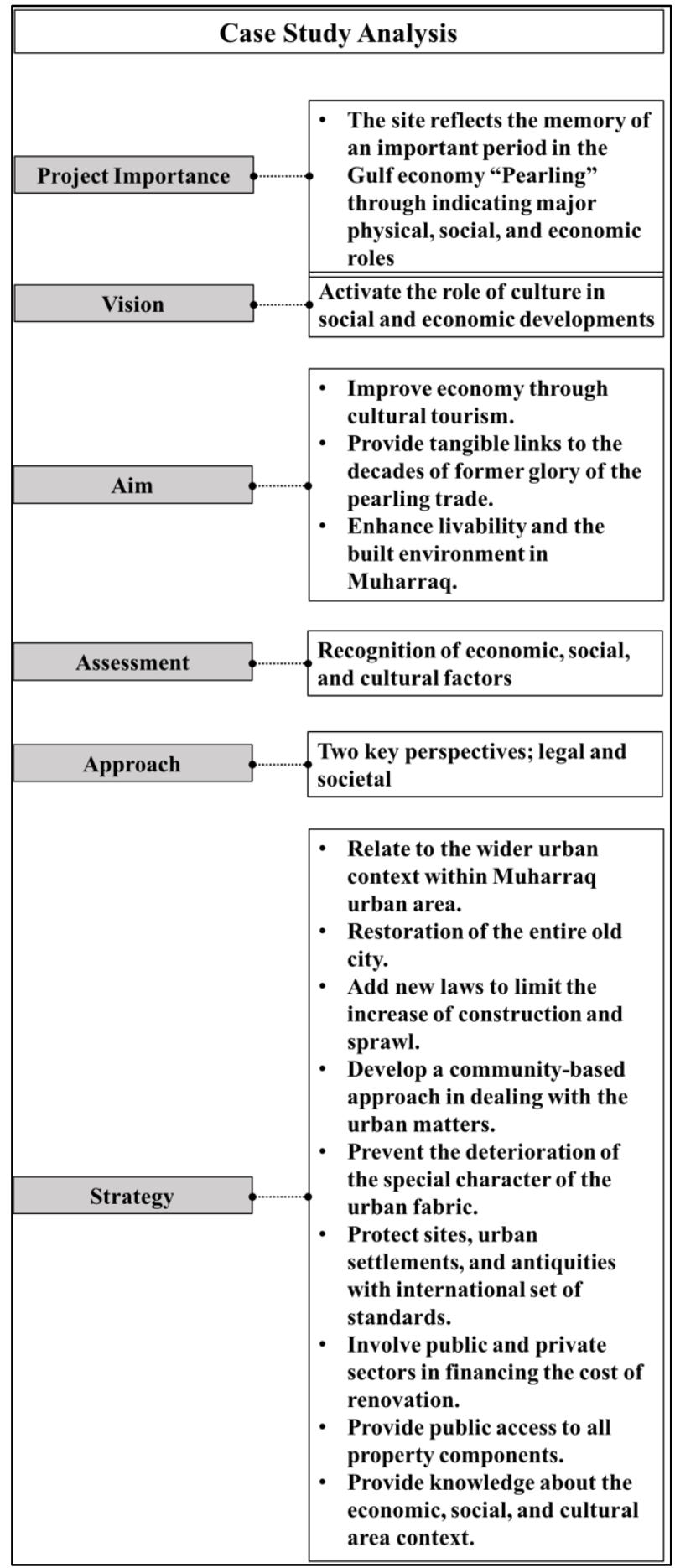

Fig-9: Summary of The Pearling Path case study. Source: Author

\section{The research design}

This research selects the Kanoo neighborhood as the study's main area of focus and develops urban regeneration strategies in terms of physical, social, and economic factors. Therefore, it is critical to develop strategies and criteria to assess the investigated site and develop a master plan of the neighborhood and its context that proposes revitalization that is compatible with Bahrain National Vision 2030 and city planning.
The site was chosen because of its important built heritage and its strategic location. It is characterized by its old traditional residential areas that consist of courtyards and blank exteriors and its narrow cul-de-sac alleys for privacy. The objective of the study was to develop an analysis and master plan of the neighborhood and reach findings and conclusions that appropriately answer the research questions of this research study: (1) How can we assess and use the existing assets in the site to revitalize the neighborhood? (2) How can we connect the neighborhood with the surrounding context?

The design of this research study takes a qualitative approach and is divided into two main stages: (1) a review of related literature to provide a better understanding of the main concepts of sustainability and urban regeneration in addition to the case study of The Pearling Path in Muharraq city and the methods used to measure its culture and tourism strategies which helped establish guidelines and assessment criteria for site analysis including ways to improve and enhance it to revitalize the neighborhood; (2) primary and secondary data collection through observation and direct inspection of the neighborhood and its surroundings, along with diagrams, existing maps and pictures relevant to the topic. Data about Bahrain, and specifically Manama and Muharraq was retrieved from interviews and documents from the Ministry of Works, Municipalities Affairs and Urban Planning, and Bahrain Authority for Culture and Antiquities, and Bahrain National Vision 2030. The research study was developed within a three-month period; therefore it was limited by time and distance [36-38]

\section{DATA ANALYSIS}

After reviewing the literature and identifying the strategies and principles of urban regeneration, as well as collecting the necessary data to carry out the neighborhood analysis, a list of criteria was developed to further guide the analysis and findings process:

- Determine the location of the neighborhood and its surrounding,

- Identify the physical, social, environmental and economic aspects,

- Develop an urban regeneration master plan.

Findings were discussed with field experts, summarized and listed along with discussion, followed by concluding remarks and implications for practice and further advancement of the research. Figure 10 below shows a diagram explaining the methodology process. 


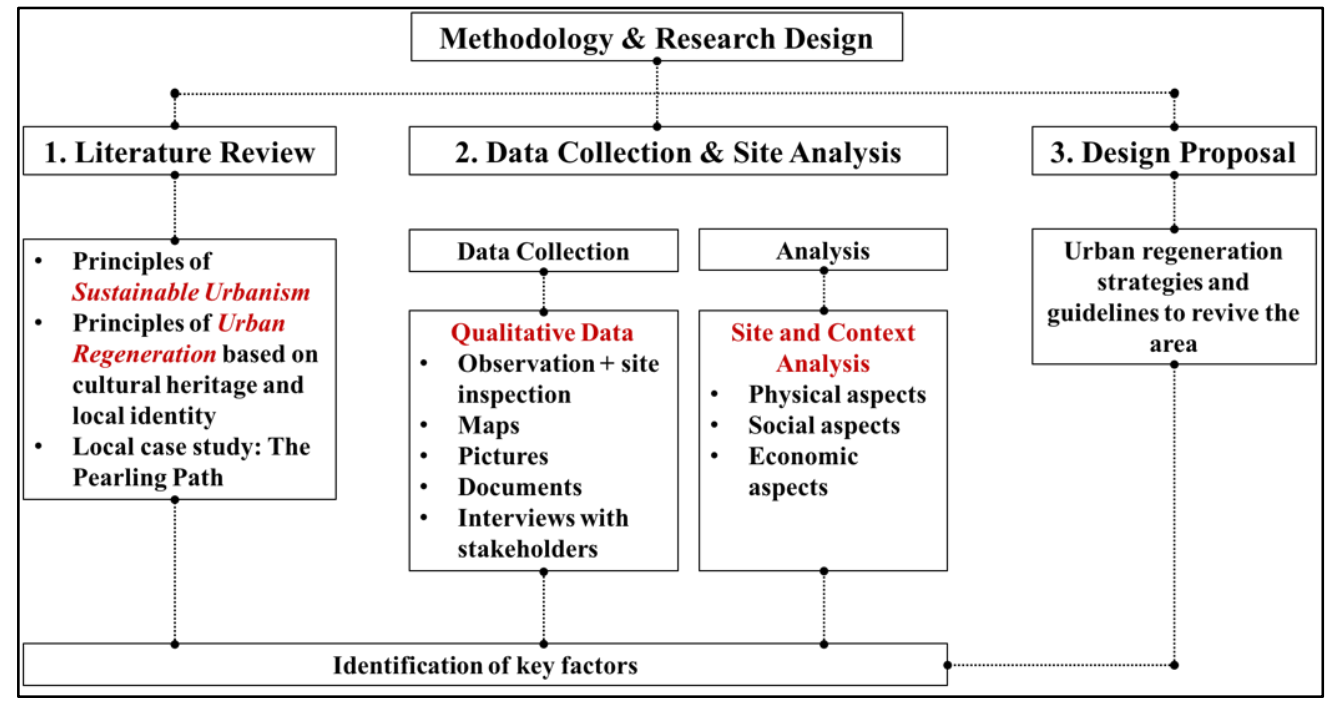

Fig-10: Diagram of methodology and research design. Source: Authors

\section{FINDINGS}

\section{Study Area: Kanoo Neighborhood}

Kanoo neighborhood is an old neighborhood close to Manama Souq and is located in the heart of Manama and consists of an area of 23 acres (Figure 11). It is located close to other traditional neighborhoods which formed the core of Manama before the expansion of the city in the twentieth century. The inhabitants of the neighborhood are diverse in religion and doctrine, and they all lived with each other in intertwined and cordial relationships. The neighborhood was characterized by love, tolerance and cooperation among each other in the joys and sorrows, which had a significant impact in developing Bahrain economically, politically, and culturally. The following sections describe the site's physical, social, and economic characteristics.

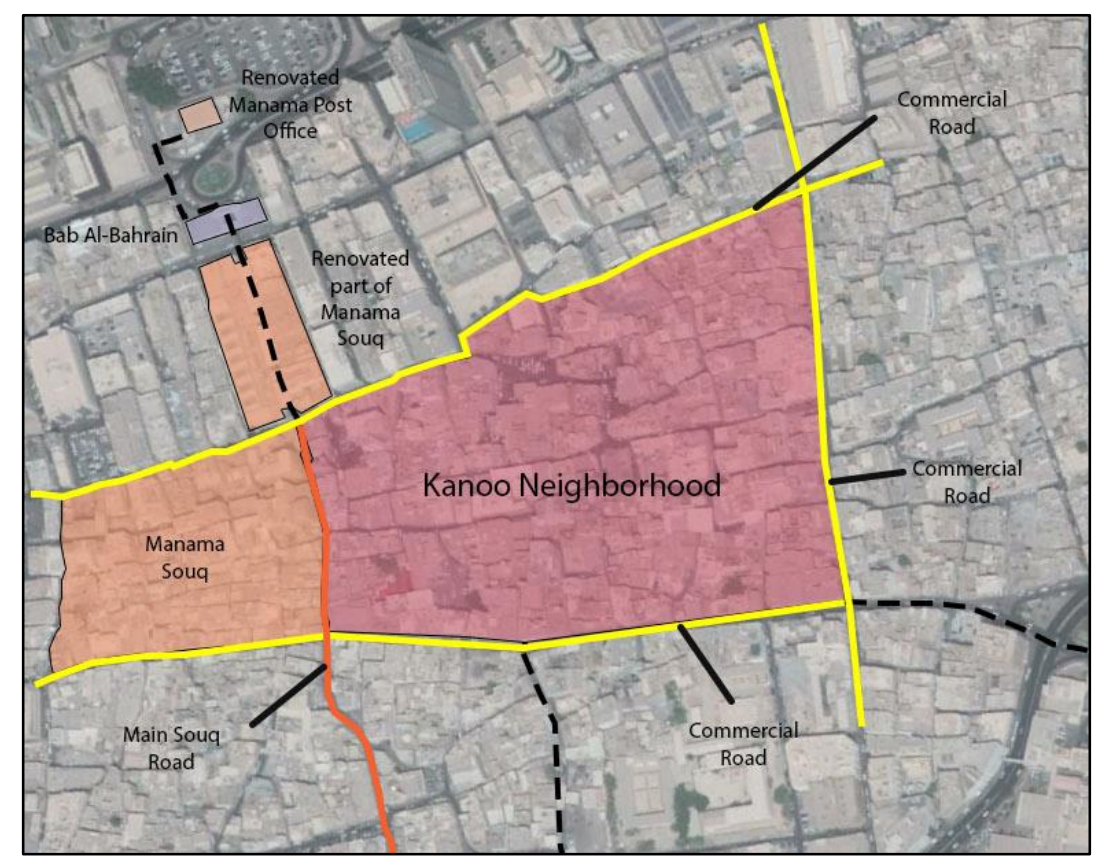

Fig-11: Map of the study area. Source: Author

\section{Site characteristics \\ Physical}

Land use

The land-use map illustrates that the neighborhood incorporates residential areas, commercial areas, a historic district, religious areas, public administrative areas, and parking lots. The map also shows the surrounding context of the neighborhood. Most of land use is classified as residential areas, followed by commercial areas. The intensity of these areas varies from one to three stories and one to 10 stories, respectively. In addition, some structures are historic structures, and their condition varies from good to bad. Some of these structures are houses of one to three stories, while others are high-rise buildings with an intensity of on to10 stories. Also, the 
neighborhood contains several religious structures dedicated to different religious groups such as mosques, matams (congregational buildings), and a Buddhist temple. Administrative buildings include schools and governmental institutions. The few parking areas range from public paid to private paid to restricted areas.

\section{Transportation and street network}

The area is surrounded by Government Road from the north and Shaikh Abdullah Avenue from the south, and from the east by Shaikh Isa Road, and Bab Al Bahrain Avenue from the west. All of these roads are considered commercial. The site is mainly accessed by cars, by bicycles that laborers use, or by foot. Public transportation points are mainly bus stations, and they are located around the edges of the old Manama city, because the old and narrow streets restrict the bus movements. Also, due to it being an old city, it was not designed for vehicles; rather it was designed for pedestrians and bicyclists. Thus, the neighborhood has insufficient parking lots and a few pedestrian walkways, which were adequate at the time the city was built. This has resulted in different behaviors.
Pedestrians started to walk on vehicle roads, and drivers park in the middle of streets or in pedestrian walkways.

Even though many people reach their desired destination using bicycles or by foot, however, the site lacks adequate walkways, safe crossings, bicycle lanes, and pedestrianized roads. The only street that has been completely blocked from cars and turned into a pedestrian street is the access from Bab-al-Bahrain and the newly renovated part of the souq.

The interconnected internal street network and alleys is interesting. It consists mainly of narrow alleys which were originally used for pedestrians. Now, after the invasion of automobiles, these alleys were transformed into roads that have only one lane for oneway traffic. These roads also have narrow pedestrian walkways constructed on their edges (Figure 12). The pedestrian walkways are very weak and can barely accommodate more than one or two people in some parts. The walkways are also not designed for the elderly or people with special needs.
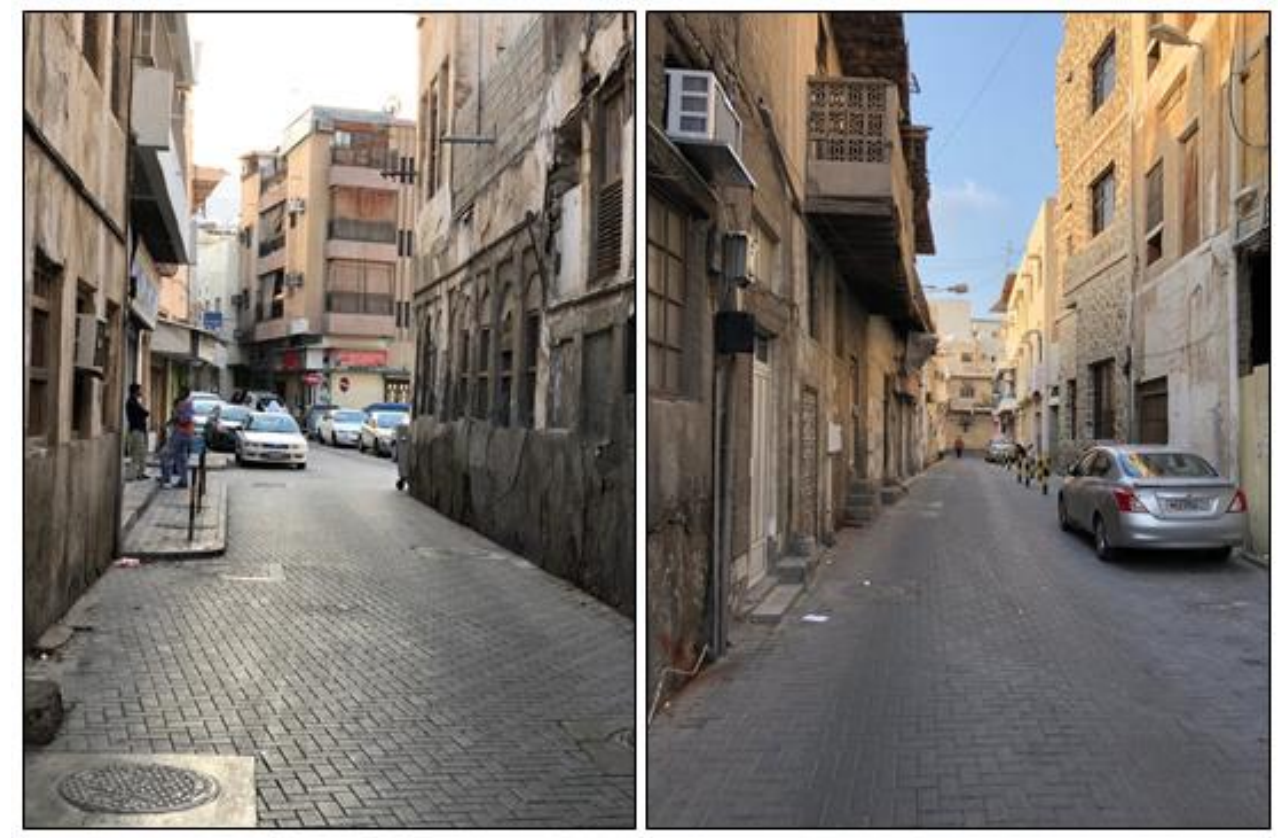

Fig-12: Narrow streets showing car blocking streets. Source: Author

The condition of most of the paved roads is moderate to bad, while a few have undergone reconstruction and have a decorative pattern. These roads are well connected, which provides an easy pedestrian flow from destination to another. Also, these roads are easily accessible from several streets. The access to the neighborhood is mainly through main roads, which are King Faisal Highway from the north and west, Al Fatih Highway from the east, and Salmaniya Road from the south.

\section{Historic structures}

There are many unique old structures included in the site which can be used as an important part of in the urban regeneration process (Figure 13). Since the neighborhood is more than 50 years old, the quality of those structures varies from good to bad according to the surveys conducted by The Bahrain Authority for Culture and Antiquities (BACA). BACA is making huge efforts to evaluate the condition of those structures and determine whether to conserve or demolish them. 


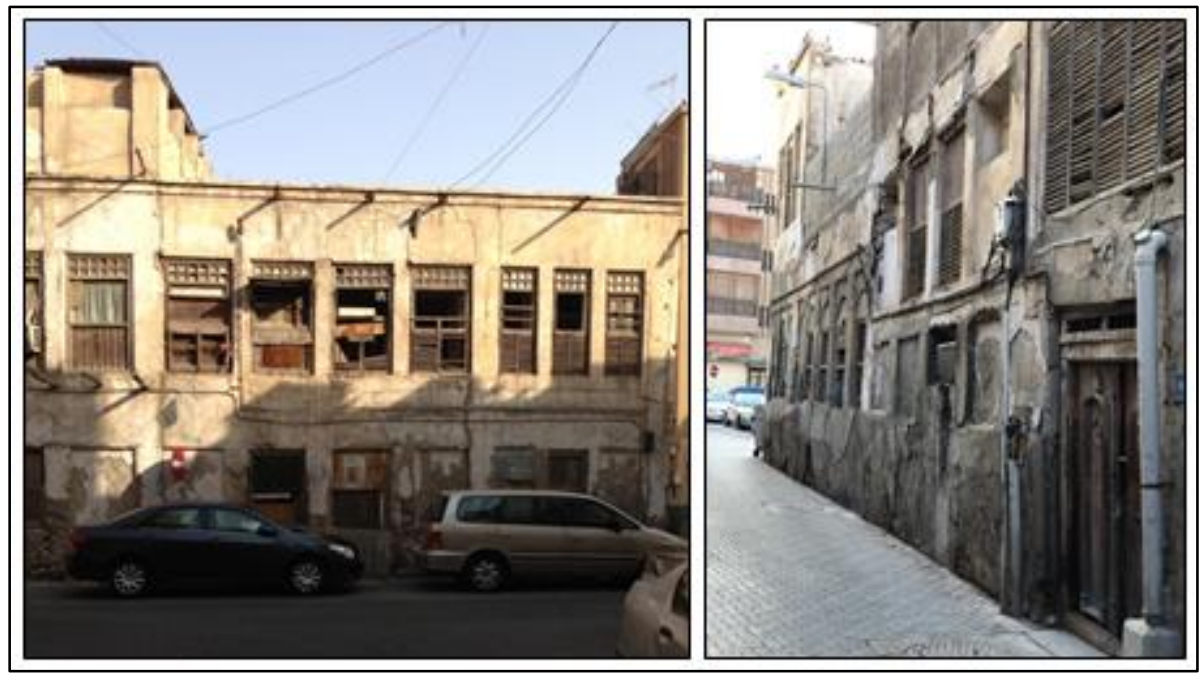

Fig-13: Historic structures in Kanoo neighborhood. Source: Authors

\section{Social}

For a long period of time, the neighborhood has accommodated different groups of people from different backgrounds and cultures. In Manama, onethird of the population is expatriates. The nationalities include local Bahrainis, Persians, and Asian laborers in search for a better living mainly from India, Bangladesh, and Pakistan. Also, people of different religions live there, such as Muslims of different sects, Oriental Christians, Jews, Hindus, and Buddhists. We can see different religious structures in the neighborhood, such as mosques, congregation halls, churches, and temples as seen in Figures 14 and 15. This has resulted in a diversified culture, and exchange of thoughts between inhabitants. For example, smells and odors of Indian cuisine spread throughout the area. Retail shops sell traditional Bahraini and Indian clothes to serve the needs of various people. BACA [11] conducted several projects in the neighborhood to promote diversity and multiculturalism. For example, the project Little India involved conservation and restoration work as well as including a small public space as meeting point for different cultures.

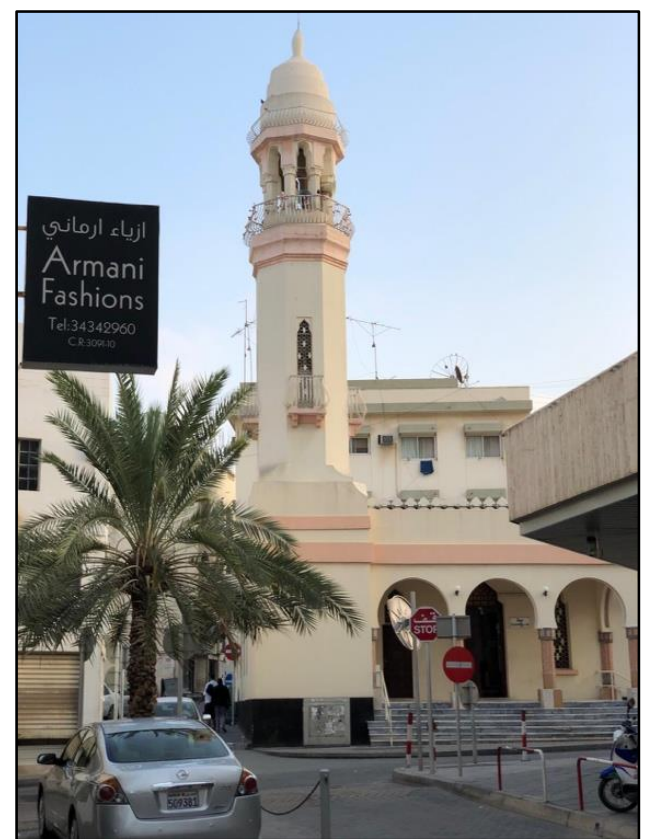

Fig-14: Mosque in Kanoo neighborhood. Source: Authors

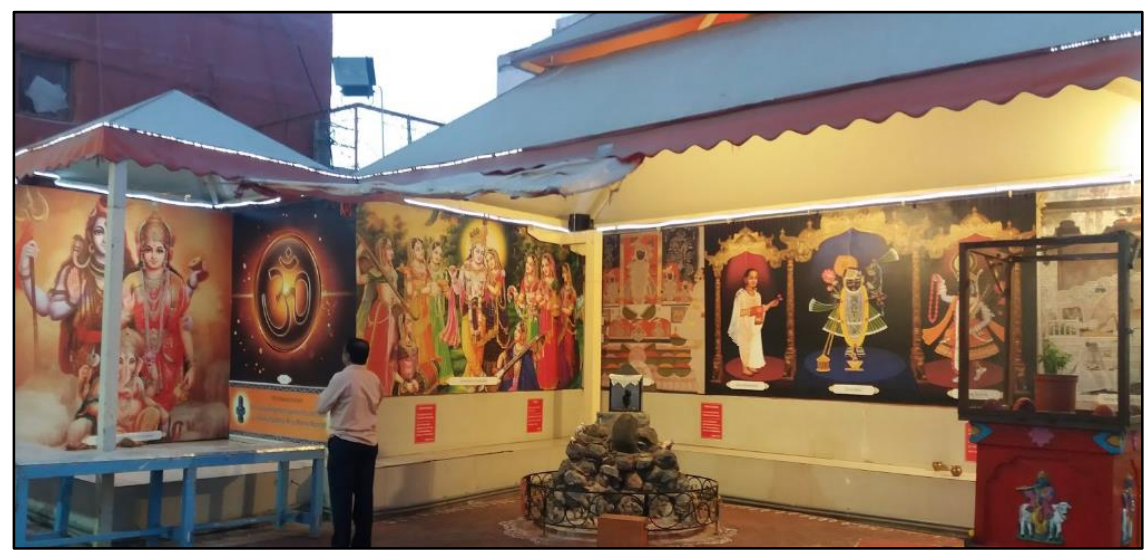

Fig-15: Shri Krishna Hindu Temple. Source: Unnikrishnan, S.

In addition to this, the social ties in the neighborhood are strong and still maintain the traditions and customs of the Bahraini society, reflecting the social structure and individual identity. Relationships of 
extended Bahraini families who lived in the neighborhood for decades and few others who live there are still solid, even though the families currently living there have been replaced with nuclear families. This change has affected family bonds and ties. However, relationships are still considered good between families and neighbors. The atmosphere in the old neighborhoods is different than in modern towns in Bahrain. For example, people still visit and contact each other within walking distance just as in the past. During ceremonial occasions and festivals, families gather together, and neighbors bring food as part of their culture and community norms. Also, socializing in the neighborhood occurs in mosques, majlis, congregational halls, sikka (narrow alleys), in traditional qahwa (café).

\section{Economic}

In addition to dense residential areas, the site features compacted commercial areas (Figure 16). These areas are mainly consisting of main branches of banks and retail shops consisting of stores with refrigerated foods, laundry, cafes, and restaurants. The economy is mainly dependent on transit trade and imports. The site also includes the Shaikh Abdulla Road that is connected directly to the souq, and it has several gold and pearl shops as Bahrain is well known for fine jewelry making.
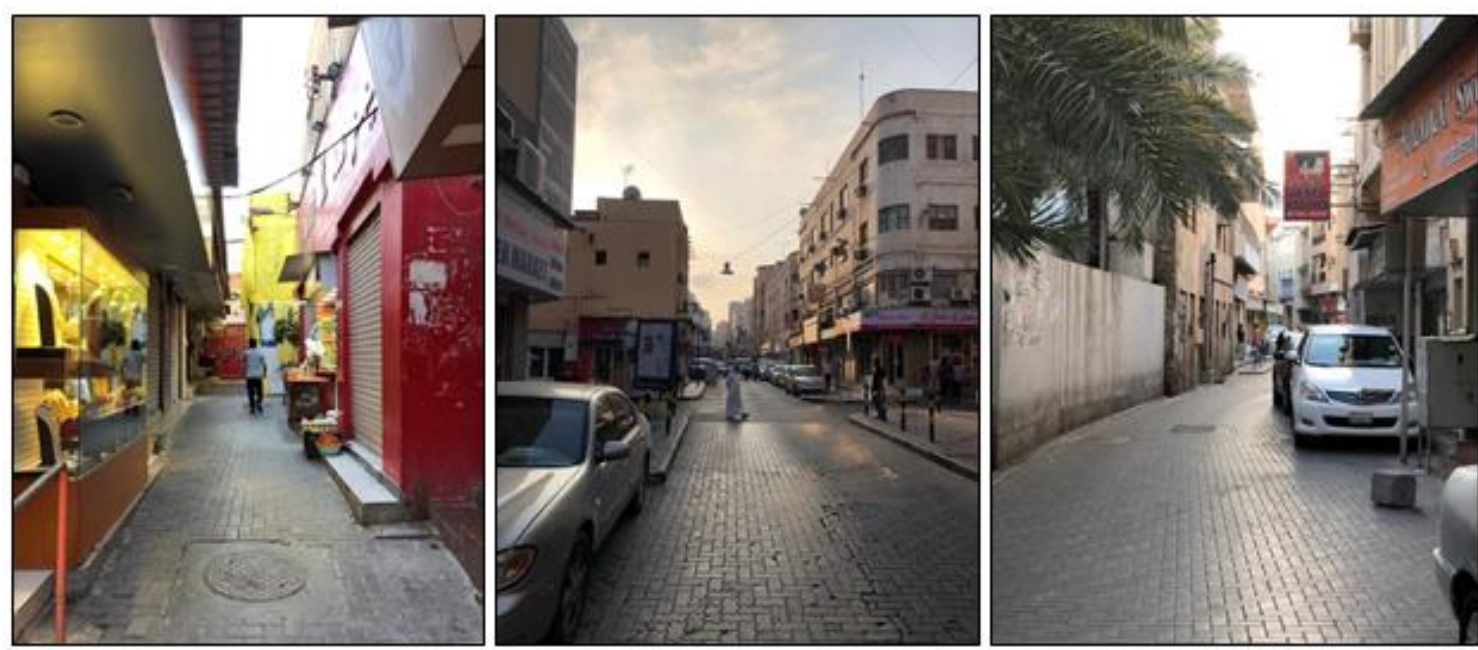

Fig-16: Commercial roads in the neighborhood. Source: Authors

\section{DISCUSSION}

The team[39-41] discussed several methods and actions related to the urban regeneration approach and classified them according to physical, social, and economic aspects. This section of the paper adopts similar approaches and develops them according to the neighborhood's situation and unique characteristics. Similarly, the strategies are classified under three categories: physical, social, and economic, as follows:

\section{Physical}

- Manage and maintain the built environment and improve its quality;

- Improve the poor and deteriorated conditions of the houses and conserve them according to international standards as they are part of the heritage and identity of the neighborhood and tell the story of its inhabitants;

- Electronically link all new and renovation building application in the neighborhood with BACA for further approval;

- Provide suitable public amenities;

- Design safe public spaces and urban green areas;

- Add continuity to the pedestrian street network by unifying the pavements;
- Increase walkability and create bicycle lanes in the neighborhood and reduce the extensive use of cars through adding traffic-calming techniques;

- Limit car access to the neighborhood to elderly and people with special needs;

- Convert some roads into pedestrianized roads;

- Increase the use of public transportation by adding more bus stops;

- Convert vacant spaces above retail spaces into flats and facilitate it by reducing business rate and giving public assistance;

- Improve the quality of life by developing digital and telecommunication use.

\section{Social}

- Involve local people in the charitable giving decision-making process of the neighborhood management;

- Developing community facilities that reflect locals' priorities;

- Create powerful incentives for authorities and others to assist neighborhood renewal;

- Penalize individuals or organizations for violating the regulations related to planning conditions, noise pollution, littering, unauthorized dumping and other forms of anti-social behavior; 
- Ensure accessibility of the neighborhoods of lowincome housing through connecting them with public transportation;

- Maintain a safe neighborhood that is secured and prevent crime;

- Create socio-cultural activities related to special occasions of different religions and cultures;

- Promote diversity and multiculturalism.

\section{Economic}

- Allocate funds to manage and maintain the urban environment;

- Obligate owners to sell their abandoned sites or buildings;

- Impose taxes on vacant undeveloped land or landowners are holding onto unnecessarily;

- Nourish the local business through establishing jointly funded management with local authorities to boost the economy;
- Engage the public and private sectors in financing the developments;

- Provide incentives for building owners, developers, investors, to support to the urban regeneration of the neighborhood.

The urban regeneration of the neighborhood needs coordination of efforts and a city-wide approach. It also needs partnership with community groups to support local economic development and to provide social initiatives to engage with the process. These stakeholders need to improve their skills, knowledge and resources to develop a powerful community that makes wise actions and is able to do thing properly. Figure 17 shows a summary of the neighborhood design proposal.

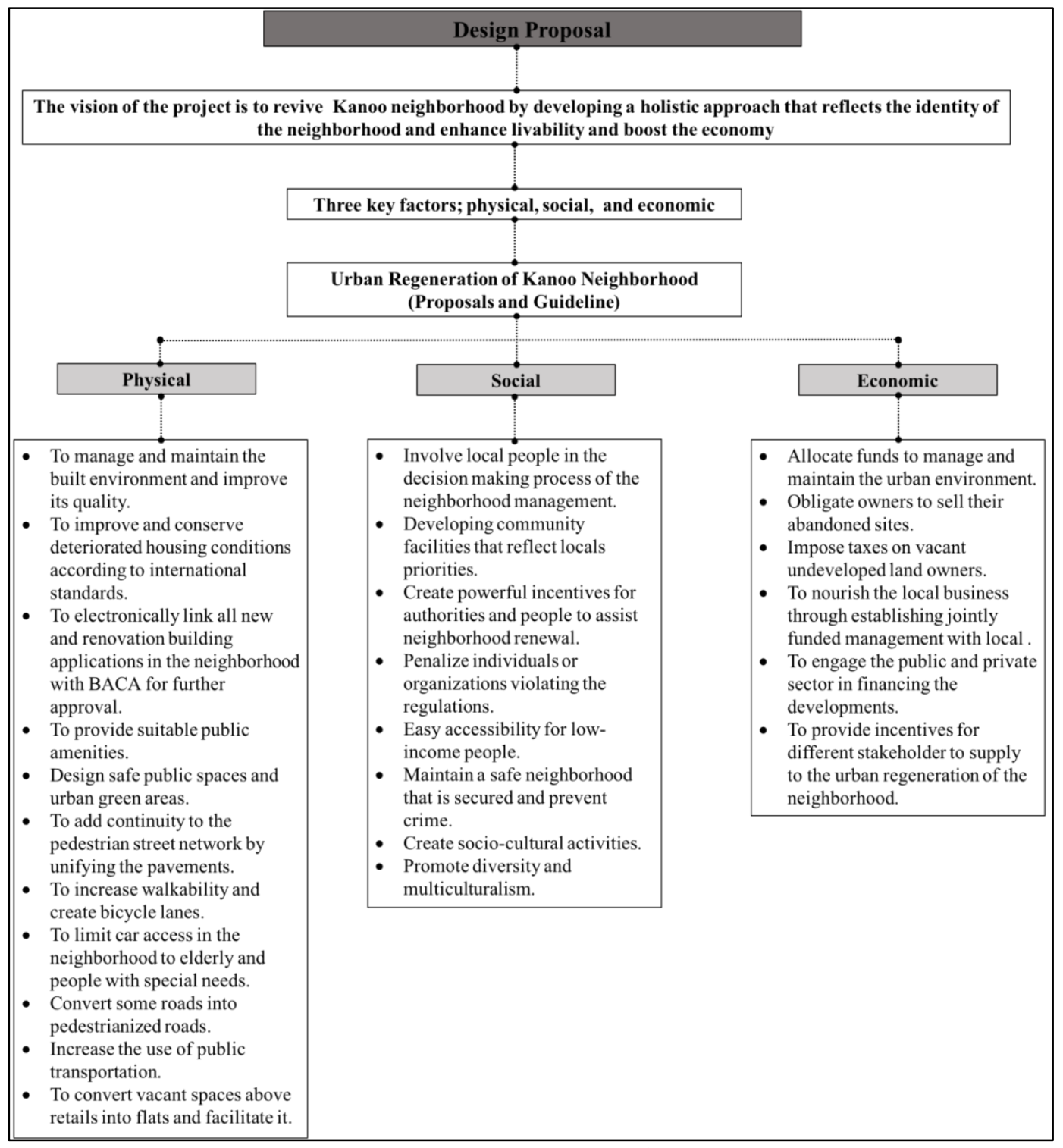

Fig-17: Diagram of the design proposal. Source: Authors 


\section{CONCLUSIONS}

Globalization has affected cities all over the world, especially in the Gulf region. These cities have been facing challenges and difficulties related to the economy, social issues, and the environment. In Bahrain rapid urbanization, which was a result of the discovery of oil, globalization, and the urge for economic developments, has affected historic cities such as Muharraq and Manama. Consequently, traditional neighborhoods have faced major transformations and serious issues that led to their abandonment and deterioration. This research focuses on the revitalization of the Kanoo neighborhood and bringing life back to this neglected quarter which is physically, socially, and economically important. This research was done through conducting a site analysis and assessment of the current condition of the neighborhood. The site analysis was divided into three types of urban regeneration: physical, social, and economic.

The findings explained the current physical condition of the site's land use, transportation and street network, and existing historic structures. The findings included a discussion of the social structure of the neighborhood and the many different types of people living there, which led to transforming the neighborhood into a vibrant multicultural neighborhood. In addition to that, the findings discussed the economic factors that consist mainly of commercial roads and retail shops within the residential quarter. As a result, several urban regeneration strategies classified into physical, social, and economic aspects have been developed to solve the problems in the neighborhood and revive it through transforming it into a focal point of attraction. These strategies are considered as a turning point to the neighborhood and can contribute to the existing initiatives created by BACA to conserve historic buildings in Manama and create urban regeneration projects. Therefore, this project can serve as a guideline and starting point to the future regeneration of the neighborhood.

\section{Implications for practice and advancement of research}

The research discusses current issues facing cities all over the world and more specifically Gulf cities. The same issues are shared among different cities in the Gulf. However, each city reflects its own uniqueness. The methodology adopted in this research can be designed to fit other similar research and to be suitably further developed. Also, the discussion section along with its strategies can be redesigned according to the uniqueness of each study. Due to limitation of time, the focus area of the research was limited to physical, social, and economic features of the site. Therefore, further research about Kanoo neighborhood is needed to reach solid effective solutions. Furthermore, researchers, planners and professionals can utilize the research and focus on the advancement and development of the findings for future studies.

\section{ACKNOWLEDGEMENTS}

Fatima Shubbar holds a bachelor's degree in Architecture from the University of Bahrain (Kingdom of Bahrain), and currently, she is undertaking a master's degree in Urban Design and Planning at Qatar University. She has 5 years of work experience as an architect.

Raffaello Furlan holds bachelors and master's degrees from IUAV University in Venice (Italy), and a $\mathrm{PhD}$ in Architecture from Griffith University in Brisbane (Australia). He has held visiting and permanent positions in Australia (University of Queensland and Griffith University in Brisbane), UAE (Canadian University of Dubai), and Qatar (Qatar University). He has taught Art History, History of Architecture, Project Management, Urban Design, Architecture Design, and Interior Design. His areas of interest include Vernacular Architecture, Architecture and Urban Sociology, Project management, and Art History. A member of the Board of Architects in Italy and Australia, he has 20 years of professional experience, divided between design management, project management and supervision roles. These were with some highly respected companies, 6 years of which were in Italy, 10 years in Australia, and 4 years in the Middle East.

This research study was developed as an assignment for the core course, 'Urban Design in Practice' (MUPD711, Fall-2018) taught by Dr. Raffaello Furlan at Qatar University, College of Engineering, Department of Architecture and Urban Planning (DAUP), for the Master in Urban Planning and Design Program (MUPD). The authors would like to acknowledge the research-oriented vision of Qatar University as an academic institute supporting sustainable development in the State of Qatar.

The authors would like to express their gratitude to the leading planners and architects of Qatar's government agencies and ministries, namely the Ministry of Municipality and Environment (MME), Qatar Rail, Qatar Museum Authority, Ashgal Public Works Authority, and Qatar Rail for their collaboration, for participating in the meetings, sharing visual data and cardinal documents relevant to the research aims, and for discussing the results and conclusion of this investigation. Finally, the authors thank the anonymous reviewers for their comments, which contributed to an improvement of this paper. The authors are solely responsible for the statements made herein.

\section{REFERENCES}

1. Furlan, R., \& Al-Mohannadi, A. (2018). The Practice of City Planning and Design in the Gulf Region: The Case of Abu Dhabi, Doha and 
Manama. International Journal of Architectural Research-ArchNet-IJAR, 12(2), 126-145.

2. Furlan, R., \& Alattar, D. (2017). Urban Regeneration in Qatar: A Comprehensive Planning Strategy for the Transport Oriented Development (TOD) of Al-Waab. Journal of Urban Regeneration and Renewal, 11(2), 168-193.

3. Furlan, R., \& ElGihani, H. (2018). Post 2022 FIFA World Cup in the State Qatar: Urban Regeneration Strategies for Doha'. Journal of Urban Regeneration and Renewal, 11(4), 355-370.

4. Furlan, R., \& Saleh, D. (2018). Sustainable Neighborhoods: West Bay, Business District of Doha (State of Qatar). Saudi Journal of Engineering and Technology, 3(8), 529-546.

5. Furlan, R., \& Alfaraidy, M. (2017a). Sense of Community in Al-Wakrah City: Strategies for the Development of Sustainable Communities in Qatar. Saudi Journal of Engineering and Technology, 2(10), 390-402.

6. Furlan, R., \& Al-Harami, A. (2019). Socio-Cultural Factors embedded into the Urban Fabric of $\mathrm{Al}$ Zubarah City in Qatar: An Urban Regeneration Vision for Contemporaneous Islamic Urbanism. Journal of Urban Regeneration and Renewal, 12(2), 151-176.

7. Furlan, R., \& AL-Mohannadi, A. (2019). SocioCultural Patterns in Domestic Spatial Form: A Comparative Study of Traditional and Modern Qatari Houses. Journal of Urban Regeneration and Renewal, 12(4), 1-23.

8. Furlan, R., \& Almohannadi, M. (2016). Light Rail Transit and Land Use: An Integrated Planning Strategy for Al-Qassar's TOD in Qatar. International Journal of Architectural ResearchArchNet-IJAR, 10(3), 170-192.

9. Furlan, R., Petruccioli, A., \& Jamaleddin, M. (2019). The authenticity of place-making: space and character of the regenerated historic district in Msheireb, Downtown Doha (State of Qatar). International Journal of Architectural ResearchArchNet-IJAR, 13(1), 151*168.

10. Furlan, R., \& Saeed, M. A. (2019). TransitOriented Development in West Bay, Business District of Doha, State of Qatar: A Strategy for Enhancing Liveability and Sense of Place. Journal of Cultural Heritage Management and Sustainable Development, $\quad$ https://doi.org/10.1108/JCHMSD09-2018-0062.

11. Bahrain Authority for Culture and Antiquities (2018). Manama, City of Trade, Multiculturalism and Religious Coexistence. Retrieved from Bahrain:

12. Al-Nabi, M. N. (2012). The History of Land use and Development in Bahrain. Bahrain: Information Affairs Authority.

13. Elsheshtawy, Y. (2008). The Evolving Arab City: Tradition, Modernity \& Urban Development. Oxfordshire, United Kingdom: Routledge.
14. Planning, G. D. o. U. (2008). Bahrain National Strategic Plan 2030: Bahrain National Plan. Retrieved from

15. Smith, S. (2017). Bahrain's Pearling Path. Retrieved from http://www.aramcoworld.com/ptBR/Articles/September-2017/Bahrain-s-PearlingPath

16. Al-Khalifa, H. M. K. H. b. I. (2008). From Regional Pioneer to Global Contender: The Economic Vision 2030 for Bahrain. Retrieved from Kingdom of Bahrain:

17. Ministry of Municipalities Affairs and Urban Planning. (2006). Capacity-Building for Enhancement of Urban Governance: Urban Design Projects for Traditional Areas in Bahrain. Stage One: Strategies and Policies. Retrieved from Kingdom of Bahrain:

18. Board, B. E. D. (2017). National Development Strategy. Retrieved from http://bahrainedb.com/about-us/nationaldevelopment-strategy/

19. Farr, D. (2008). Sustainable Urbanism - Urban Design with Nature. Hoboken, New Jersey (USA): John Wiley \& Sons, Inc.

20. Furlan, R. (2016). Modern and Vernacular Settlements in Doha: An Urban Planning Strategy to Pursue Modernity and Consolidate Cultural identity. Arts and Social Sciences Journal, 7(2), 171-176.

21. Furlan, R., \& Faggion, L. (2017). Urban Regeneration of GCC Cities: Preserving the Urban Fabric's Cultural Heritage and Social Complexity. Journal of Historical Archaeology \& Anthropological Sciences, 1(1), 1-16.

22. Oktay, D. (2012). Human Sustainable Urbanism: In Pursuit of Ecological and Social-Cultural Sustainability. Procedia - Social and Behavioral Sciences, 36, 16-27.

23. Roggema, R. (2016). The future of sustainable urbanism: a redefinition. City, Territory and Architecture, 3(22), 1-12.

24. Furlan, R., \& Mogra, S. (2017). Public Realm at Qatar University Campus: Perception and sustainability of Open Green Spaces. Saudi Journal of Humanities and Social Sciences, 2(1), 80-94.

25. Furlan, R., Petruccioli, A., Major, M., Zaina, S., Saeed, M. A., \& Saleh, D. (2018). The Urban Regeneration of West-Bay, Business District of Doha (State of Qatar): A Transit Oriented Development Enhancing Livability. Journal of Urban Management, 8(1), 126-144.

26. Furlan, R., \& Tannous, H. (2018). Livability and Urban Quality of the Souq Waqif in Doha (State of Qatar). Saudi Journal of Engineering and Technology, 3(6), 368-387.

27. Sadahiro, Y. (2008). Spatial Data Infrastructure for Urban Regeneration. Japan: Springer.

28. Furlan, R., \& Faggion, L. (2015). The Souq Waqif Heritage Site in Doha: Spatial Form and Livability. 
American Journal of Environmental Engineering, 5(5), 146-160.

29. BOCA, M. C. (2018). Urban Regeneration Through Culture. Romanian Review on Political Geography, 1, 36-40.

30. Furlan, R., \& Alfaraidy, M. (2017b). Urban Form and Sense of Community: Exploring the Catalyst for Community Sustainability for Alwakrah Neighbourhood. Architecture Research, 7(4), 123145.

31. Furlan, R., \& Saeed, M. A. (2017). Strategies for the Enhancement of Users' Social Interactions in Al Mirqab Al Jadeed Street in Doha, State of Qatar. Architecture Research, 7(3), 69-83.

32. Son, M. (2018). 'Urban regeneration' to 'Social regeneration':

33. Horita, M., \& Koizumi, H. (2009). Innovations in Collaborative Urban Regeneration. Japan: Springer.

34. UNESCO. (2012). Pearling, Testimony of an Island Economy. Retrieved from http://whc.unesco.org/en/list/1364

35. Antiquities", B. A. f. C. a. (2017). Pearling Path. Retrieved from www.pearlingpath.bh
36. Creswell, J. (1994). Research Design: Qualitative and Quantitative Approaches. Thousand Oaks, California: Sage Publications.

37. Denzin, N. K., \& Lincoln, Y. S. (2005). The Sage Handbook of Qualitative Research. London: Sage Publications.

38. Marshall, C., \& Rossman, G. B. (2010). Designing Qualitative Research (3 ed.). California: Sage Publication.

39. Domain 4 Team. (2003). Domain 4- Performance Based Built Environment. Retrieved from http://www.reading.ac.uk/PeBBu/state_of_art/actio ns.htm

40. Furlan, R., \& Sipe, N. (2017). Light Rail Transit (LRT) and Transit Villages in Qatar: A PlanningStrategy to Revitalize the Built Environment of Doha. Journal of Urban Regeneration and Renewal, 10(4), 1-20.

41. Culture and social regeneration through the Culture City of East Asia event initiative in Cheongju South Korea. (Doctor of Philosophy). University of Sheffield, United Kingdom. 